\title{
Maraviroc in Treatment-experienced Patients with HIV-1 Infection - EXPERIEnCE From Routine Clinical PRACTICE
}

\author{
S. Reuter ${ }^{1}$, P. Braken 1 , B. Jensen ${ }^{1}$, S. Sierra-Aragon ${ }^{2}$, M. Oette ${ }^{3}$, M. Balduin², R. Kaiser ${ }^{2}$, D. Häussinger ${ }^{1}$ \\ ${ }^{1}$ Clinic for Gastroenterology, Hepatology and Infectious Diseases, University Hospital, Düsseldorf, Germany, \\ ${ }^{2}$ Institute of Virology, University Hospital of Cologne, Germany, \\ ${ }^{3}$ Hospital Augustinerinnen, Cologne, Germany
}

\begin{abstract}
Objective: Few data are available about the efficacy of maraviroc (MVC) during routine use. We characterized indications for MVC use and the efficacy of MVC in clinical practice.

Methods: Thirty-two patients treated with MVC at our institution between 2006 and 2009 were included. Genotypic $(\mathrm{n}=31)$ and phenotypic $(\mathrm{n}=13)$ tropism analysis was performed. We determined indications for MVC use, characteristics of antiretroviral combination partners and treatment outcome.

Results: Complete suppression of viral replication was achieved in $78 \%$ after 6 months. A median increase of $124 \mathrm{CD}^{+}$cells/ $\mu \mathrm{l}$ after 6 months was observed. Concordance between phenotypic and genotypic tropism was found in $75 \%$. Indications for MVC treatment included treatment failure $(\mathrm{n}=15)$, intolerance to previous antiretrovirals $(\mathrm{n}=6)$ and add-on MVC for intensification without changing the current regimen ( $\mathrm{n}=$ 11). The add-on strategy was used in patients with a relatively low viremia in order to achieve complete viral load suppression or in situations with suppressed viral load but judged as unstable due to an extensive resistance pattern. Salvage drugs most frequently combined with MVC were darunavir $(\mathrm{n}=14)$ and raltegravir ( $\mathrm{n}=14)$.

The genotypic assay had predicted CXCR4 tropism in 5 patients, using a false positive rate (FPR) of $20 \%$. Lowering the FPR to $5 \%$ predicted CCR 5 tropism in 4 cases, still resulting in sustained complete viral response under MVC use.

Conclusions: MVC containing salvage regimens achieve relevant CD4 cell increases and high viral response rates. In patients with few remaining treatment options it may be justified to lower the FPR-cutoff to $5 \%$ when predicting the coreceptor usage. Hereby, MVC could still be applied in selected patients with otherwise limited treatment options.
\end{abstract}

Key words: CCR-5, CXCR-4, salvage, genotype, resistance testing

\section{INTRODUCTION}

HIV-1 enters target cells through interaction between its envelope glycoprotein (gp120) and the CD4 receptor and a chemokine co-receptor on the human cell. CCR5 and CXCR4 are the two principal co-receptors involved in HIV entry in vivo. Viruses with an exclusive affinity for the CCR5 co-receptor are called CCR5-tropic (R5), whereas those viruses binding to the CXCR4 co-receptor are known as CXCR4-tropic (X4). R5 viruses predominate during early phases of HIV-infection, whereas X4 strains are mainly found during advanced stages of disease [1]. In some patients, both X4 and R5 tropic viruses are found concurrently, named dual or mixed viral populations.

Maraviroc (MVC) is the first CCR5 co-receptor inhibitor. Because of its mode of action the use of MVC is restricted to patients harboring virus able to bind only to the CCR 5 receptor. The selection of usually pre-existing virus strains able to bind to the CXCR4 receptor is the most important mechanism to evade CCR5 antagonists. Thus, a major challenge prior to the use of MVC is the obligatory tropism testing. Tropism testing is used to identify patients most likely to benefit from treatment regimens that include a CCR5 antagonist and to monitor patients on treatment for the emergence of virus populations that have switched their coreceptor usage. Tropism can be assessed by phenotypic [2] and genotypic assays [3].

In two large trials in patients with multiple class resistance, MOTIVATE 1 and 2, it was shown that MVC plus optimized background treatment (OBT) was associated with greater virologic and immunologic efficacy as compared to placebo plus OBT [4]. Simultaneously to the introduction of MVC in 2007, various antiretroviral drugs such as the protease inhibitor (PI) darunavir (DRV), the integrase inhibitor raltegravir (RAL) or the second generation non-nucleoside reverse-transcriptase inhibitor (NNRTI) etravirine (ETR) were newly introduced. Due to these new treatment options, current treatment guidelines now state that the goal of antiretroviral therapy is viral load (VL) suppression to $<50$ copies $/ \mathrm{ml}$ for all patients, included those with heavy pre-treatment [5].

It appears particularly important to position MVC in the clinical context of the widened spectrum of available treatment options and it remains a challenge to define situations in which this new drug should be used in the clinical routine [6]. In this prospective observational study we analysed the characteristics of all patients treated with MVC at our institution between 2006 and 2009 to obtain information on the optimal use of MVC in routine clinical practice. 


\section{Materials And Methods}

In the outpatient clinic of the Department of Gastroenterology, Hepatology and Infectious Diseases of Düsseldorf University a total of 32 treatment-experienced patients received MVC for a minimum of 6 months since 2006 . They were prospectively followed for a median of 16 months (interquartile range 12-21 months). In addition, 55 patients had been tested for their viral coreceptor usage, but $\mathrm{X} 4$-using viruses were reported and therefore MVC could not be prescribed.

We determined indications for MVC use, the most frequent combinations with other antiretrovirals as well as the number of new combination partners, comorbidities and treatment outcome. All patients received an analysis of the receptor status (CCR5 or CXCR4), and we performed a comparative evaluation of phenotypic assay (Trofile test) and genotypic tropism testing. By additional RT/PR + gp41 genotypic resistance analysis, we determined the sensitivity score as an indicator for the number of effective additional drugs in the OBT.

\section{DEFINITIONS}

Salvage drugs: This term comprised darunavir, raltegravir, etravirine, enfuvirtide, and tipranavir (DRV, RAL, ETR, ENF and TPV).

Partial treatment response: Patient reaches a VL below 400 copies / $\mathrm{ml} 3$ months after starting a regime containing MVC, but cannot be suppressed below VL detection limit of 50 copies / $\mathrm{ml}$ after 6 months.

Complete treatment response: After starting a MVC containing regimen, the VL is suppressed below detection limit of 50 copies $/ \mathrm{ml}$ at 3 months or 6 months, respectively.

Sustained complete treatment response: After starting a MVC containing regimen, the VL is suppressed below detection limit of 50 copies / $\mathrm{ml}$ until last observation. Primary treatment failure: Patient cannot be suppressed below a VL of 400 copies / ml 3 months after starting a regime containing MVC.

Secondary treatment failure: After a complete treatment response, the VL again rises to detectable levels at two separate time points under continued treatment.

\section{Genotypic Assay for Tropism Testing}

In the routine tropism testing, viral RNA is always first analyzed, if it yields no result, proviral DNA is sequenced. RNA is preferentially considered, as DNAsequencing results tend to overestimate $\mathrm{X} 4$ variants. Viral RNA and proviral DNA from PBMCs were isolated, the V3 loop from the gp120 region (V3) amplified and sequenced as previously described [7], using the following primers 6206EcoRI: 5'- AGAGCAGA ATTCAGTGGCAATGAGAGT -3' (nt 6206-6232) and 7785R: 5'- AGTGCT'TCCTGCTGCTCCYAAG AACCC-3' (nt 7785-7811). The V3 sequences were analyzed using the geno2pheno[coreceptor] tool (http://www.genafor.org) to predict the viral tropism using a false positive rate (FPR) cutoff of $20 \%$. FPR is the probability that "real" $\mathrm{R} 5$ viruses are predicted as X4. A high FPR cutoff (20\%) is used to ensure a most conservative prediction with the result that only few $\mathrm{R} 5$ predictions will correspond to "real" X4 samples, and therefore to minimize the risk of prescribing MVC to patients having X4 viruses. In some patients with severely limited treatment options a FPR of 5\% was also applied for the decision whether to use MVC so that these patients would not have been deprived of an important option because of a too conservative prediction (patients \#14, 15, 18, 26).

\section{Phenotypic assay for Tropism Testing (Trofile TeST)}

Samples were prepared as indicated by Monogram (Monogram Biosciences, San Francisco, CA, USA) and sent to be tested with the Trofile assay. This phenotypic test uses recombinant HIV-1 pseudo viruses and different reporter cell lines for differentiation between $\mathrm{X} 4-$ and R5 tropism.

\section{Cumulative Sensitivity Score (CSS) FOR Optimized Background TreatMent (OBT)}

The number of active drugs in the OBT concomitant to MVC administration was calculated with the prediction tools geno2pheno[integrase] (http://www.genafor.org) and HIV grade tool (http://www.hiv-grade.de). To calculate the genotypic sensitivity score, values between 0 and 1.5 were assigned to each drug according to its presumed potency in the OBT as follows:

NRTIs: fully active $=1$; intermediate $=0.3$; resistant $=0$; NNRTIs (EFV, NVP), T-20, RAL: fully active =1.5; resistant $=0$

NNRTIs (ETR): fully active $=1.5$; intermediate $=0.75$; resistant $=0$

PIs: fully active $=1.5$; intermediate $=0.5$; resistant $=0$

The calculation of genotypic sensitivity scores is an established procedure for comparative prediction of virologic outcomes according to genotypic resistance results $[8,9]$. For calculation of the CSS, a substance was only scored as fully active if drug sensitivity was shown in all previously performed analyses.

\section{RESULTS}

Table 1 depicts the most important baseline characteristics of the study group. Twenty-four patients (75\%) were heavily pre-treated (i.e. $\geq 5$ previous therapies) with a median number of 9 previous regimens prior to MVC use and a median age of 47 years at the time of MVC start (interquartile range 40-53 years).

\section{INDICATIONS FOR STARTING MVC}

Patients were divided into a group with detectable VL prior to the change to a regimen containing MVC (group $\mathrm{A}, \mathrm{n}=25$ ) and another group with a VL below the detection limit at the time of starting MVC (group $\mathrm{B}, \mathrm{n}=7$ ) (Table 1). In group $\mathrm{A}$, the 3 indications for changing to a MVC containing antiretroviral regimen 
Table 1. Baseline characteristics of patients started on MVC treatment.

\begin{tabular}{|c|c|c|c|}
\hline Characteristics & $\begin{array}{l}\text { Group } A^{1} \\
n=25\end{array}$ & $\begin{array}{l}\text { Group } \mathbf{B}^{2} \\
\mathrm{n}=7\end{array}$ & $\begin{array}{l}\text { All patients } \\
\quad \mathrm{n}=32\end{array}$ \\
\hline Gender (f /m) & $6 / 19$ & $2 / 5$ & $8 / 24$ \\
\hline Median age at start MVC (years) & 47 & 48 & 47 \\
\hline Median $\mathrm{CD} 4^{+} \mathrm{T}$ count at baseline & 364 & 235 & 306.5 \\
\hline Median VL at baseline & 829 & $<50$ copies $/ \mathrm{ml}$ & 280 \\
\hline Median number of previous drug combinations* & 9 & 10 & 9 \\
\hline Median duration of previous antiretroviral therapy (years) * & 10.2 & 8.5 & 10.1 \\
\hline Percentage with CCS of OBT $\geq 2$ & $\begin{array}{c}20 / 25 \\
(80 \%)\end{array}$ & $\begin{array}{l}5 / 7 \\
(71 \%)\end{array}$ & $\begin{array}{c}25 / 32 \\
(78 \%)\end{array}$ \\
\hline Median CCS of OBT & 2.5 & 2.0 & 2.5 \\
\hline
\end{tabular}

* Salvage drugs included darunavir, raltegravir, etravirine, enfuvirtide, and tipranavir (DRV, RAL, ETR, ENF and TPV). CCS = cumulative sensitivity score, ${ }^{1} \mathrm{HIV}-\mathrm{RNA}$ detectable at screening, ${ }^{2} \mathrm{HIV}-\mathrm{RNA}$ not detectable at screening.

included treatment failure with detectable resistance mutations ( $\mathrm{n}=15$ ), treatment failure without detectable resistance mutations (probably due to non-adherence because of intolerance to their previous PIcontaining regimen) $(\mathrm{n}=3)$ and patients with a relatively low viremia (range 50-1200 copies / ml), thus requiring add-on MVC for intensification of their regimen $(n=7)$. In 4 of these 7 patients, a full suppression of VL was achieved at month 3. After 6 months all 7 patients showed complete VL suppression.

In group $\mathrm{B}$, reasons for a change to MVC were intolerance of the previous regimen in 3 cases and addon MVC to a virologically successful regimen in order to achieve an intensification of the regimen $(n=4)$. Reasons for regimen intensification for these $4 \mathrm{pa}-$ tients in group $\mathrm{B}$ were as follows:

One patient (\#29) had never been sufficiently suppressed during the last 13 years. With the use of 3 new drugs his VL already was below 50 copies $/ \mathrm{ml}$, but the previous decline of the VL had been rather slow and a secondary failure with no further treatment options was imminent. Two further patients (\#26 and 31) also had multiresistant viruses and had repeatedly shown poor adherence to antiretroviral treatments in the past with few remaining treatment options. In order to preserve these ultimately remaining options, MVC was added for greater likelihood of long-term success. One patient (\#27) received MVC as an experimental add-on with the aim of a CD4 $\mathrm{T}$ cell count increase, as the baseline CD4 T cell count was $88 / \mu \mathrm{l}$ in spite of a long-term suppressed VL.

\section{Drug Combinations with MVC}

At the time of first use, MVC was combined with other (median 2) salvage drugs in $17 / 32$ cases (52\%). MVC was combined with 1 other salvage drug in $13 \%$, with 2 in $25 \%$, with 3 in $13 \%$ and with 4 in 3\% of cases. Salvage drugs most frequently combined with MVC included DRV ( $\mathrm{n}=14)$ and RAL $(\mathrm{n}=14)$. Other salvage drugs used were ENF $(n=3)$, ETR $(n=2)$ and TPV $(\mathrm{n}=1)$.

\section{Treatment Response}

After initiation of MVC, a complete treatment response was achieved in $24 / 32(75 \%)$ patients after 3 months and in $25 / 32(78 \%)$ after month 6 . The median increase of CD 4 cells after 3 months was $141 / \mu$, and $124 / \mu$ l after 6 months (Table 2). Patients with treatment success (complete and partial treatment response) had a median cumulative sensitivity score of 2.75 at start of MVC, while patients with treatment failure (primary and secondary) had a median score of 2.5. The median time of follow-up for patients with sustained complete treatment response $(\mathrm{n}=17)$ was 12.1 months.

In group A, the VL could be fully suppressed in 18 /25 (72\%) patients after 3 months (Table 2). In two cases with only partial response at month 3 , the MVC containing regimen was continued and complete treatment response was achieved in the long-run (patients 6 and 17).

In group B, patient 29 received a further intensification of its regimen with add-on of ETR after month 3 , because of low-level viremia. This patient currently presents with a stable VL suppression.

A total of 12 out of 32 patients (38\%) experienced treatment failure under combination treatment including MVC. In 2 patients failure of treatment was primary, while 10 patients showed secondary treatment failure.

\section{TropisM TESTING}

All patients received either genotypic or phenotypic resistance analysis at baseline, i.e. at least once during the year before receiving MVC (Table 3). In 13 out of 32 patients a phenotypic tropism result was obtained, while genotypic tropism testing was performed in 31 patients. Thus, 12 patients received both tests and test results concurred in $9(75 \%)$ cases. MVC was started with a median time of 43 days after genotypic coreceptor testing. A sustained complete treatment response was achieved in $17 / 31$ patients (55\%) after 
Table 2. Characteristics of treatment response.

\begin{tabular}{|c|c|c|c|}
\hline Characteristics & $\begin{array}{l}\text { Group } A^{1} \\
(n=25)\end{array}$ & $\begin{array}{l}\text { Group } B^{2} \\
(n=7)\end{array}$ & $\begin{array}{l}\text { All patients } \\
(\mathrm{n}=32)\end{array}$ \\
\hline Median duration of follow-up (months) & $\begin{array}{c}15 \\
(\mathrm{n}=25)\end{array}$ & $\begin{array}{c}21 \\
(\mathrm{n}=7)\end{array}$ & $\begin{array}{c}16 \\
(\mathrm{n}=32)\end{array}$ \\
\hline Median duration until VL below detection limit (days) & $\begin{array}{c}52 \\
(\mathrm{n}=24)^{*}\end{array}$ & - & $\begin{array}{c}52 \\
(\mathrm{n}=24)^{*}\end{array}$ \\
\hline Median increase in $\mathrm{CD}^{+}{ }^{+} \mathrm{T}$-cell count at month 3 & $\begin{array}{l}112 \text { cells } / \mu l \\
\quad(\mathrm{n}=25)\end{array}$ & $\begin{array}{l}21 \text { cells } / \mu \mathrm{l} \\
(\mathrm{n}=7)\end{array}$ & $\begin{array}{l}141 \text { cells } / \mu \mathrm{l} \\
\quad(\mathrm{n}=32)\end{array}$ \\
\hline Median increase in $\mathrm{CD}^{+}{ }^{+} \mathrm{T}$-cell count at month 6 & $\begin{array}{l}96 \text { cells } / \mu \mathrm{l} \\
(\mathrm{n}=25)\end{array}$ & $\begin{array}{l}88 \text { cells } / \mu \mathrm{l} \\
\quad(\mathrm{n}=7)\end{array}$ & $\begin{array}{l}124 \text { cells } / \mu \mathrm{l} \\
(\mathrm{n}=32)\end{array}$ \\
\hline Number of patients with VL below detection limit after 3 months & $18 / 25$ & $6 / 7^{* *}$ & $24 / 32$ \\
\hline $\begin{array}{l}\text { Number of patients with sustained complete response } \\
\text { (median duration of observation) }\end{array}$ & $\begin{array}{c}12 \\
\text { (11.5 months) }\end{array}$ & $\begin{array}{c}5 \\
(14.2 \text { months })\end{array}$ & $\begin{array}{l}17 \\
\text { (12.1 months) }\end{array}$ \\
\hline $\begin{array}{l}\text { Number of patients with secondary treatment failure } \\
\text { (median duration to failure) }\end{array}$ & $\begin{array}{c}8 \\
\text { (9.2 months) }\end{array}$ & $\begin{array}{c}2 \\
\text { (10 months) }\end{array}$ & $\begin{array}{c}9 \\
\text { (9.2 months) }\end{array}$ \\
\hline Number of patients with partial response & 3 & 0 & 3 \\
\hline $\begin{array}{l}\text { Number of patients with primary treatment failure } \\
\text { (median duration to failure) }\end{array}$ & $\begin{array}{c}2 \\
\text { (3.5 months) }\end{array}$ & - & $\begin{array}{c}3 \\
\text { (4.0 months) }\end{array}$ \\
\hline
\end{tabular}

*One patient never showed VL suppression (lowest VL under MVC: 1874 copies /ml).

** In one case VL was detectable at month 3 despite the addition of MVC, 1HIV-RNA detectable at screening, 2HIV-RNA not detectable at screening.

Table 3.Tropism test results and response to treatment.

\begin{tabular}{|c|c|c|c|c|c|c|c|c|c|c|}
\hline No. & $\begin{array}{c}\text { age } \\
\text { (years) }\end{array}$ & $\begin{array}{c}\text { gender } \\
(\mathrm{m} / \mathrm{f})\end{array}$ & $\begin{array}{l}\text { No. of } \\
\text { previous } \\
\text { regimens }\end{array}$ & $\begin{array}{c}\text { S OBT: } \\
\text { cummulative }\end{array}$ & $\begin{array}{c}\text { days } \\
\text { between } \\
\text { V3 } \\
\text { analysis } \\
\text { and MVC } \\
\text { start }\end{array}$ & $\begin{array}{c}\text { Predicted } \\
\text { phenotype } \\
\text { (V3) } \\
\text { before MVC }\end{array}$ & $\begin{array}{l}\text { FPR } \\
(\%)\end{array}$ & $\begin{array}{c}\text { TROFILE } \\
\text { Phenotype } \\
\text { before MVC }\end{array}$ & $\begin{array}{c}\text { overall } \\
\text { response }\end{array}$ & $\begin{array}{l}\text { Phenotype } \\
\text { after failure }\end{array}$ \\
\hline 1 & 39 & $\mathrm{~m}$ & 1 & 2,5 & 42 & R5 & 38 & - & sec.failure & X4 (FPR 16.6\%) \\
\hline$\frac{1}{2}$ & 56 & $\mathrm{~m}$ & 16 & 3,0 & 36 & R5 & 21,2 & R5 & sec.failure & R5 (FPR $23.7 \%$ ) \\
\hline 3 & 54 & $\mathrm{~m}$ & 9 & 2,0 & 26 & R5 & 24,7 & - & + & - \\
\hline 4 & 38 & $\mathrm{~m}$ & 3 & 3,5 & 10 & R5 & 23,4 & $\mathrm{D} / \mathrm{M}$ & + & - \\
\hline 5 & 43 & $\mathrm{~m}$ & 3 & 2,1 & 38 & R5 & 25 & - & + & - \\
\hline 6 & 50 & $f$ & 19 & $\frac{2,2}{1,0}$ & 16 & R5 & 38,3 & - & + & - \\
\hline 7 & 47 & $f$ & 15 & 2,0 & 57 & R5 & 33,9 & - & + & - \\
\hline 8 & 49 & $\mathrm{~m}$ & 9 & 3,0 & 0 & R5 & 79,5 & - & sec.failure & - \\
\hline 9 & 46 & $m$ & 1 & 3,0 & 205 & R5 & 96,5 & R5 & + & \\
\hline 10 & 40 & $\mathrm{~m}$ & 11 & 2,5 & 30 & R5 & 85,8 & R5 & sec.failure & R5 (FPR 65.4\%) \\
\hline 11 & 38 & $\mathrm{~m}$ & 2 & 1,5 & 49 & R5 & 47,8 & - & + & - \\
\hline 12 & 59 & $\mathrm{f}$ & 17 & 3,5 & 262 & R5 & 82,4 & - & sec.failure & X4 (FPR 74.3\%) \\
\hline 13 & 55 & $\mathrm{~m}$ & 17 & 4,6 & 187 & R5 & 96,1 & - & prim.failure & R5 (FPR 96.1) \\
\hline 14 & 67 & $\mathrm{~m}$ & 16 & 3,0 & 40 & $\mathrm{X} 4$ & 15,6 & R5 & + & - \\
\hline 15 & 64 & $m$ & 5 & 3,0 & 275 & $\mathrm{X} 4$ & 5,4 & R5 & + & - \\
\hline 16 & 47 & $\mathrm{~m}$ & 15 & 0,5 & 282 & R5 & 31,3 & R5 & sec.failure & X4 (FPR $11,4 \%$ ) \\
\hline 17 & 50 & $\mathrm{~m}$ & 6 & 2,5 & 10 & R5 & 89,7 & R5 & $(+)$ & - \\
\hline 18 & 52 & $f$ & 15 & 4,0 & 0 & $\mathrm{X} 4$ & 6 & - & + & - \\
\hline 19 & 37 & $f$ & 1 & 2,0 & 20 & R5 & 64 & R5 & $(+)$ & - \\
\hline 20 & 46 & $\mathrm{~m}$ & 19 & 0,0 & -2 & - & - & R5 & prim.failure & X4 (TROFILE) \\
\hline 21 & 44 & $\mathrm{~m}$ & 1 & 3,5 & 43 & R5 & 85,6 & - & $(+)$ & \\
\hline 22 & 48 & $f$ & 6 & 2,0 & 76 & R5 & 89,1 & R5 & sec.failure & R5 (FPR 76.9\%) \\
\hline 23 & 35 & $\mathrm{~m}$ & 13 & 1,5 & 210 & $\mathrm{X} 4$ & 1,7 & - & sec.failure & D/M (TROFILE) \\
\hline 24 & 40 & $\mathrm{~m}$ & 9 & 3,0 & 43 & R5 & 90,7 & - & + & - \\
\hline 25 & 61 & $\mathrm{~m}$ & 6 & 3,0 & 126 & R5 & 42,6 & R5 & + & - \\
\hline 26 & 42 & $f$ & 24 & 1,5 & 295 & $\mathrm{X} 4$ & 9 & - & + & - \\
\hline 27 & 61 & $f$ & 1 & 3,5 & 30 & R5 & 67 & - & + & - \\
\hline 28 & 54 & $f$ & 5 & 2,0 & 95 & R5 & 80 & R5 & + & - \\
\hline 29 & 48 & $\mathrm{~m}$ & 19 & 0,0 & 152 & R5 & 67,9 & - & sec.failure & R5 (FPR 49.7\%) \\
\hline 30 & 50 & $\mathrm{~m}$ & 11 & 3,6 & 227 & R5 & 38,4 & - & + & - \\
\hline 31 & 44 & $f$ & 10 & 4,1 & 106 & R5 & 91,2 & - & sec.failure & X4 (FPR 6\%) \\
\hline 32 & 30 & $f$ & 7 & 2,0 & 31 & R5 & 98,9 & - & + & - \\
\hline
\end{tabular}

$+=$ sustained complete treatment response, $(+)=$ partial treatment response, prim. $=$ primary, sec. $=$ secondary, $\mathrm{D} / \mathrm{M}=$ dual/mixed. 
genotypic tropism analysis and in $6 / 13$ patients $(46 \%)$ after phenotypic tropism testing (Table 3).

The Trofile test had revealed R5 virus in 12 cases, while in one case, initial screening had shown a dual/mixed tropism (patient 4). The genotypic tropism test predicted R5 viruses in $26 / 31$ (84\%) analyses. X4 viruses were predicted in patients \#14, 15, 18, 23 and 26. Four of the latter would have been predicted R5 by the genotypic assay at a FPR of 5\% and complete suppression of VL has persisted in these 4 patients.

Tropism testing was additionally performed in 11 out of 12 cases after primary or secondary treatment failure. X4 or dual/mixed virus tropism was documented in 6 out of 12 cases. In 5 cases, R 5 viruses persisted despite failure (poor adherence could not be excluded in 2 cases and a weak OBT was evident in 3 cases).

\section{SAFETY PROFILE}

MVC containing regimens were generally well tolerated. At 3 or 6 months after starting MVC, newly elevated transaminases $(<3 \mathrm{x}$ upper normal limit) were noted in 4 patients (\#7, 10, 22 and 30) and newly elevated GGT ( $<3 \mathrm{x}$ upper normal limit) was noted in $2 \mathrm{pa-}$ tients (\#13 and 16). While patient 10 had replicative $\mathrm{HBV}$ infection, drug adverse events (due to MVC or the OBT) could not be excluded as the cause of elevated liver parameters in the remaining cases.

\section{Discussion}

This prospective, observational study was performed in an unselected patient population between the years 2005 and 2008. A total of 87 patients were tested for their viral tropism status and 55 were reported to harbour X4 viruses, while 32 started MVC treatment.

\section{INDICATIONS FOR MVC USE}

Available studies indicate that MVC is a useful therapeutic adjunct in heavily pre-treated patients $[4,10]$. In our study, indications for choosing a MVC-containing regimen were either intolerance to a previous regimen or as add-on medication for intensification of the current regimen in approximately half of patients, while patients with virological treatment failure comprised the other half of patients. Treatment failure and sideeffects are well-known causes for a change of the antiretroviral regimen. However, the addition of a drug for further intensification of a current regimen is a newly emerging treatment strategy. At our institution, this strategy has become more frequent with the advent of new drug classes for salvage treatment. Addon MVC for regimen intensification was successfully applied in 12 cases. In 7 cases, VL could only be fully suppressed after addition of MVC. In the other 5 cases, the VL was suppressed under the current regimen, but the situation was judged as unstable due to few remaining treatment options and an extensive resistance pattern. Here, a continued suppression of VL was documented for a median duration of observation of 16 months after adding MVC.

\section{CD4 ${ }^{+}$-CELL COUNT INCREASE}

Despite heavy pre-treatment, pronounced increases of $\mathrm{CD}^{+}{ }^{+}$-cells counts under MVC have been repeatedly described. Saag and co-workers observed that MVC in patients with dual or mixed tropism viral populations did not result in improved viral suppression, but led to a greater $\mathrm{CD}^{+}$-cell count increase as compared to placebo [11]. In the MOTIVATE trials, pooled data showed a CD $4^{+}$-cell increase of 124 cells $/ \mu$ for MVC applied twice daily [4]. The median increase of $\mathrm{CD}^{+}{ }_{-}$ cells in our survey was 124 cells $/ \mu$ after 6 months (table 2) and was hereby comparable to the numbers from the MOTIVATE trials. In addition, our analysis revealed that in patients with detectable VL at baseline, the greatest increase of $\mathrm{CD}^{+}{ }^{+}$-cells was observed during the first 3 months of treatment with a slow increase hereafter.

A widely accepted theory for early CD4 cell increase after introduction of ART is the resolution of lymphocyte sequestration in tissue sites and redistribution of these lymphocytes into the blood. This mechanism may explain the early increase of CD4 cells in group A.

Interestingly, in patients with suppressed VL at baseline (group B) the largest increase of $\mathrm{CD}^{+}{ }^{+}$-cells was observed between months 3 and 6. We may speculate that this delayed increase of CD4 cells might represent a different mechanism of immune reconstitution.

\section{TREATMENT RESPONSE}

Despite heavy pre-treatment in $75 \%$ of our patients, $72 \%$ achieved a full VL-suppression at 12 weeks in patients with detectable VL at baseline. Notably, this success rate is higher than the success rates in the MOTIVATE trials, where less than 40\% reached full VL-suppression at week 12 [4]. Our markedly higher rate of VL suppression can be explained by the frequent use of new potent drugs in the OBT, such as DRV, RAL and ETR. These drugs had not been available in the MOTIVATE studies. However, it must be noted that treatment outcomes may also have been biased due to the small number of total patients in our cohort.

Treatment failure under a MVC containing regimen does not necessarily imply a switch of receptor tropism from R5 to X4. Only 4 of our patients had a documented switch in the genotypic analysis from R5 to X4 using viral strains. In a sub-analysis of the MOTIVATE trials, $\mathrm{X} 4$ viruses were observed in more than $50 \%$ of patients under MVC at the time of failure [10]. This finding is consistent with the increased sensitivity for detection of low levels of pre-existing virus binding to CXCR4, when CCR5-tropic variants are selectively suppressed. The predominance of X4-strains at the time of failure is analogous to the selection of archived drug-resistant virus leading to reduced efficacy when failed antiretroviral therapy is reinitiated after the interruption of treatment [12].

\section{IMPORTANCE OF OBT}

It was repeatedly shown that potent, fully active new drugs in the background regimen have an additional 
beneficial effect when therapy with MVC is initiated $[10,13,14]$. In some patients, the original regime did not lead to VL suppression. However, adding further salvage drugs or adapting the OBT to newly occurring mutations increases the chances of suppressing the VL below the detection limit. In our analysis, 8 out of 32 patients with a new MVC containing regimen could not be fully suppressed after month 3 . VL could be successfully suppressed below the detection limit in 1 of these patients after addition of another salvage drug (ETR).

One objective measurement for the number of available susceptible co-medications is the Cumulative Sensitivity Score (CSS) for the OBT. In the CSS a drug is only considered fully active if all previous genotypic analyses have revealed sensitivity [15]. A slightly higher CSS at start of MVC was seen in patients with complete and partial treatment response (median CSS 2.75) as compared to patients with treatment failure (median CSS 2.5). This finding underscores the importance of a potent OBT in combination with MVC.

\section{Tropism TESTING}

Tropism testing is mandatory prior to the use of MVC. To date, all major MVC clinical trials have been performed with the phenotypic Trofile assay [4, 10], able to detect minority subpopulations with alternate tropisms when present at 5 to $10 \%$, or up to $0.3 \%$ with the new Trofile ES assay. Unfortunately, performance of the phenotypic Trofile assay is restricted to one location in California, USA, produces high costs, requires a minimal VL of 1000 copies / $\mathrm{ml}$ and a delay of 3-6 weeks until receipt of results, hereby prohibiting timely treatment decisions $[16,17]$.

Due to the above disadvantages, centers are increasingly applying genotypic tropism testing, whose accuracy is similar to the Trofile assay [18-23]. It was shown that genotypic tropism testing is more cost-effective and time-saving and can be performed with low VL $[3,16]$. Currently, few clinical data on the use of the genotypic assay are available $[21,22]$. The value of the genotypic assay as an alternative to phenotypic testing was confirmed in the present study. A sustained suppression of viral replication was at least as frequently achieved after genotypic tropism analysis as compared to the Trofile test (55\% vs. $46 \%$ ). We found conscordance between phenotypic and genotypic test results in $75 \%$ of cases (using a FPR of $20 \%$ ). In analogy, Poveda and co-workers found a concordance of the assays in $72 \%$ of cases [20]. In general, a good response to MVC in patients with predicted R5 viruses was documented, irrespective of the tropism test used.

FPR is the probability that "real" R5 viruses are predicted as X4. For the discrimination between R5 and $\mathrm{X} 4$ viruses, the FPR is classically set at a high cutoff-level of $20 \%$. This is a very conservative set point in order to minimize the risk of predicting a $\mathrm{R} 5$ virus although $\mathrm{X} 4$-using viruses are present. Using this conservative cutoff value, 5 patients had predicted X4 viruses. The corresponding FPRs were determined below $20 \%$ but above $5 \%$ in 4 cases (patients \#14, 15, $18,26)$. MVC was used in these patients due to severely limited treatment options and excellent treatment results were obtained in all 4 patients. This example demonstrates that lowering the FPR to 5\% may be justified in selected cases with multiresistant viruses, in order to preserve MVC as an important option. Using a cutoff of $5 \%$ the concordance between the genotypic and phenotypic analyses was $92 \%$.

After treatment failure, tropism testing was performed in $11 / 12$ cases. X4 or dual/mixed tropism was documented in $6 / 11$ cases, while R5-virus persisted despite failure in 5 cases. These findings suggest that despite documented R5-viruses, additional reasons may account for treatment failure of a MVC containing regimen, including poor treatment adherence and insufficient potency of the OBT. In failing cases with R5-persistence, the OBT contained further salvage drugs in 4 out of 5 cases at the time of failure. As a reason for failure, poor adherence had to be assumed in 2 cases (as a consequence regimen was not changed), while a weak OBT was evident in 3 cases (as a consequence further sensitive drugs were added to the regimen).

Treatment failure occurring despite persistence of an $\mathrm{R} 5$ receptor status has been previously observed [10] with $43 \%$ of patients being R5 at the time of failure. Resistance to MVC while maintaining CCR5-tropism has been discussed as another possibility for treatment failure, but appears to be a rare event in vivo [24].

\section{CONCLUSIONS}

With the recent advent of new treatment options in HIV-medicine, complete suppression of HI-viral load has again become an attainable goal for many heavily pre-treated patients. MVC containing salvage regimes achieve relevant $\mathrm{CD}^{+}{ }^{+}$-cell increases and high viral response rates. In some patients, the time until complete suppression of VL may be prolonged beyond the first 3 months of treatment. In clinical routine, MVC is frequently combined with other new antiretroviral drugs, especially DRV and RAL. Reasons for choosing MVC as a combination partner included treatment failure and intolerance of the previous antiretroviral regimen. In addition, add-on MVC for regimen intensification is a newly emerging treatment strategy. This option is especially promising because of the good tolerability and safety profile of MVC. In patients with few remaining treatment options it may be justified to lower the cutoff for the FPR used when predicting the coreceptor usage from $20 \%$ to $5 \%$. Hereby, MVC can still be applied in selected patients with otherwise limited treatment options. The value of the genotypic assay as an evolving alternative to phenotypic testing was confirmed in the present study and has become the standard assay for tropism testing at many institutions.

\section{REFERENCES}

1. de Mendoza C, Rodriguez C, Garcia F, Eiros JM, Ruiz L, Caballero E, Aguilera A, Leiva P, Colomina J, Gutierrez F, del RJ, Aguero J, Soriano V. Prevalence of X4 tropic viruses in patients recently infected with HIV-1 and lack of association with transmission of drug resistance. J Antimicrob Chemother 2007 Apr;59(4):698-704. 
2. Braun P, Wiesmann F. Phenotypic assays for the determination of coreceptor tropism in HIV-1 infected individuals. Eur J Med Res 2007 Oct 15;12(9):463-72.

3. Lengauer T, Sander O, Sierra S, Thielen A, Kaiser R. Bioinformatics prediction of HIV coreceptor usage. Nat Biotechnol 2007 Dec;25(12):1407-10.

4. Gulick RM, Lalezari J, Goodrich J, Clumeck N, DeJesus E, Horban A, Nadler J, Clotet B, Karlsson A, Wohlfeiler M, Montana JB, McHale M, Sullivan J, Ridgway C, Felstead S, Dunne MW, van der RE, Mayer H. Maraviroc for previously treated patients with R5 HIV-1 infection. N Engl J Med 2008 Oct 2;359(14):1429-41.

5. Hammer SM, Eron JJ, Jr., Reiss P, Schooley RT, Thompson MA, Walmsley S, Cahn P, Fischl MA, Gatell JM, Hirsch MS, Jacobsen DM, Montaner JS, Richman DD, Yeni PG, Volberding PA. Antiretroviral treatment of adult HIV infection: 2008 recommendations of the International AIDS Society-USA panel. JAMA 2008 Aug 6;300(5):555-70.

6. Dolin R. A new class of anti-HIV therapy and new challenges. N Engl J Med 2008 Oct 2;359(14):1509-11.

7. Balduin M, Sierra S, Daumer MP, Rockstroh JK, Oette M, Fatkenheuer G, Kupfer B, Beerenwinkel N, Hoffmann D, Selbig J, Pfister HJ, Kaiser R. Evolution of HIV resistance during treatment interruption in experienced patients and after restarting a new therapy. J Clin Virol 2005 Dec;34(4):277-87.

8. Maggiolo F, Airoldi M, Callegaro A, Ripamonti D, Gregis G, Quinzan G, Bombana E, Ravasio V, Suter F. Prediction of Virologic Outcome of Salvage Antiretroviral Treatment by Different Systems for Interpreting Genotypic HIV Drug Resistance. J Int Assoc Physicians AIDS Care (Chic Ill ) 2007 Jun;6(2):87-93.

9. Anderson JA, Jiang H, Ding X, Petch L, Journigan T, Fiscus SA, Haubrich R, Katzenstein D, Swanstrom R, Gulick RM. Genotypic susceptibility scores and HIV type 1 RNA responses in treatment-experienced subjects with HIV type 1 infection. AIDS Res Hum Retroviruses 2008 May;24(5):685-94.

10. Fatkenheuer G, Nelson M, Lazzarin A, Konourina I, Hoepelman AI, Lampiris H, Hirschel B, Tebas P, Raffi F, Trottier B, Bellos N, Saag M, Cooper DA, Westby M, Tawadrous M, Sullivan JF, Ridgway C, Dunne MW, Felstead S, Mayer H, van der RE. Subgroup analyses of maraviroc in previously treated R5 HIV-1 infection. N Engl J Med 2008 Oct 2;359(14):1442-55.

11. Saag M, Goodrich J, Fatkenheuer G, Clotet B, Clumeck N, Sullivan J, Westby M, van der RE, Mayer H. A doubleblind, placebo-controlled trial of maraviroc in treatmentexperienced patients infected with non-R5 HIV-1. J Infect Dis 2009 Jun 1;199(11):1638-47.

12. Deeks SG, Grant RM, Wrin T, Paxinos EE, Liegler T, Hoh R, Martin JN, Petropoulos CJ. Persistence of drugresistant HIV-1 after a structured treatment interruption and its impact on treatment response. AIDS $2003 \mathrm{Feb}$ 14;17(3):361-70.

13. Hicks CB, Cahn P, Cooper DA, Walmsley SL, Katlama C, Clotet B, Lazzarin A, Johnson MA, Neubacher D, Mayers D, Valdez H. Durable efficacy of tipranavir-ritonavir in combination with an optimised background regimen of antiretroviral drugs for treatment-experienced HIV-1-infected patients at 48 weeks in the Randomized Evaluation of Strategic Intervention in multi-drug reSistant patients with Tipranavir (RESIST) studies: an analysis of combined data from two randomised open-label trials. Lancet 2006 Aug 5;368(9534):466-75.

14. Steigbigel RT, Cooper DA, Kumar PN, Eron JE, Schechter M, Markowitz M, Loutfy MR, Lennox JL, Gatell JM, Rockstroh JK, Katlama C, Yeni P, Lazzarin A, Clotet B, Zhao J, Chen J, Ryan DM, Rhodes RR, Killar
JA, Gilde LR, Strohmaier KM, Meibohm AR, Miller MD, Hazuda DJ, Nessly ML, DiNubile MJ, Isaacs RD, Nguyen BY, Teppler H. Raltegravir with optimized background therapy for resistant HIV-1 infection. N Engl J Med 2008 Jul 24;359(4):339-54.

15. Flandre P, Descamps D, Morand-Jouberd L, Charpentier C, Delaugerre C, Chaix ML, et al. Comparison of the use of last genotype versus all past genotypes to classify patients according to resistance algorithms. 2009 Nov 11; Cologne, Germany 2009 p. 33.

16. Vandekerckhove L, Verhofstede C, Vogelaers D. Maraviroc: integration of a new antiretroviral drug class into clinical practice. J Antimicrob Chemother 2008 Jun;61(6):1187-90.

17. Whitcomb JM, Huang W, Fransen S, Limoli K, Toma J, Wrin T, Chappey C, Kiss LD, Paxinos EE, Petropoulos CJ. Development and characterization of a novel singlecycle recombinant-virus assay to determine human immunodeficiency virus type 1 coreceptor tropism. Antimicrob Agents Chemother 2007 Feb;51(2):566-75.

18. Stucki H, Wagner S, Vidal V, Hamy F, Klimkait T. HIV tropism testing using sequence and structure information of the V3 loop. 2009 Jul 19; Cape Town, South Africa 2009.

19. Poveda E, Briz V, Quinones-Mateu M, Soriano V. HIV tropism: diagnostic tools and implications for disease progression and treatment with entry inhibitors. AIDS 2006 Jun 26;20(10):1359-67.

20. Poveda E, Seclen E, Gonzalez MM, Garcia F, Chueca N, Aguilera A, Rodriguez JJ, Gonzalez-Lahoz J, Soriano V. Design and validation of new genotypic tools for easy and reliable estimation of HIV tropism before using CCR5 antagonists. J Antimicrob Chemother 2009 May;63(5):1006-10.

21. Recordon -Pinson P, Descamps D, Soulié C, Lazrek M, Charpentier C, Montes B, et al. Genotypic prediction of HIV-1 tropism: correlation with the virological response to maraviroc and genetic evolution on maraviroc therapy in the genotropism study. 2009 Nov 11; Cologne, Germany 2009 p. 33.

22. Sierra S, Thielen A, Jensen B, Esser S, Fatkenheuer G, Lengauer $\mathrm{T}$, et al. Tropism determination and clinical outcomeof49 patients from the AREVIR cohort under MVC treatment. 2009 Nov 11; Cologne, Germany 2009 p. 47.

23. Harrigan PR, MOTIVATE Tropism Study Group. "Deep" sequencing to identify treatment experienced patients who respond to maraviroc (MVC). 2009 p. Abstract PE 3.3/2.

24. Jubb R, Lewis M, Simpson P, Craig C, Haddrick M, Perros M, et al. CCR5-tropic Resistance to Maraviroc Is Uncommon even among Patients on Functional Maraviroc Monotherapy or with Ongoing Low-level Replication. 2009 Feb 16; Montréal, Canada 2009.

Received: April 18, 2010 / Accepted: June 8, 2010

\section{Address for correspondence:}

Stefan Reuter, MD

Department of Gastroenterology, Hepatology and

Infectious Diseases

University Hospital of Düsseldorf

Moorenstr. 5

40225 Düsseldorf

Germany

Phone: +49-211-81-16331

Fax: +49-211-81-16022

E-mail: Stefan.reuter@med.uni-duesseldorf.de 